\title{
InVESTigation OF NUMERiCAl Simulation PARAMETERS ON FLUID FLOW AROUND TRASH-RACKS
}

\author{
Zoran Čarija, Ivana Lučin, Bože Lučin \& Luka Grbčić
}
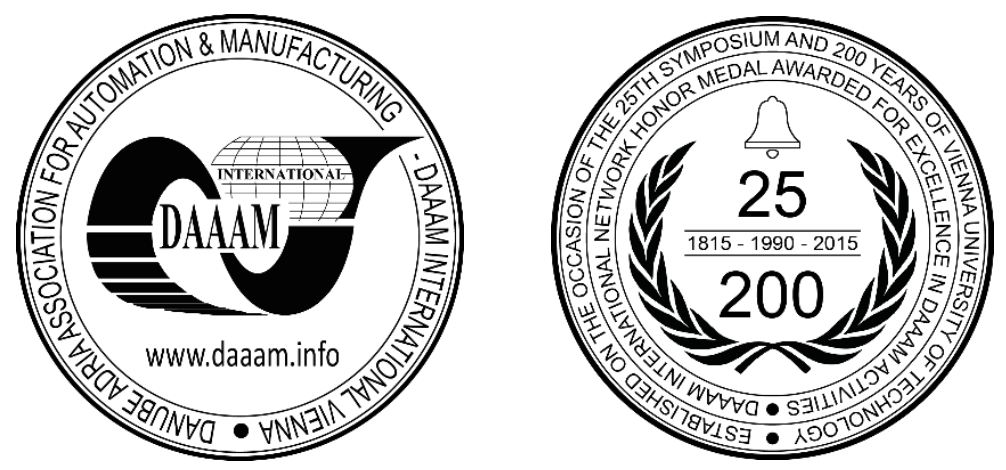

This Publication has to be referred as: Carija, Z[oran]; Lucin, I[vana]; Lucin, B[oze] \& Grbcic, L[uka] (2018). Investigation of Numerical Simulation Parameters on Fluid Flow Around Trash-Racks, Proceedings of the 29th DAAAM International Symposium, pp.1046-1052, B. Katalinic (Ed.), Published by DAAAM International, ISBN 978-3-90273420-4, ISSN 1726-9679, Vienna, Austria

DOI: $10.2507 / 29$ th.daaam.proceedings.149

\begin{abstract}
Trash-racks provide protection for hydraulic turbines by blocking entrance of large debris that could damage turbine parts. Trash-racks also help reduce fish injuries and mortality caused with fish entrapment in turbine. Installation of trash-racks is necessary, but causes inevitable head losses that decrease water turbine energy production. With increasing ecological concerns different bar-rack configurations are examined to provide better fish protection, mostly not considering head losses. Experimental results of head losses caused by trash-racks found in literature are conducted on scaled models due to experiment facility limitations while number of investigated configurations is limited with cost of production. Most head loss equations derived from experimental results are valid only in specific range of parameters. Considering these limitations, numerical simulations would enable investigation of a large number of trash-rack combinations, where simulations can be conducted for turbine intake geometries made in full scale. In this work numerical simulation results will be compared with experimental results from literature. Geometry, mesh and simulation parameters will be investigated, considering influence on simulation results agreement with experiment. Guidelines for numerical simulation setup will be provided for future work where investigation of trash-rack configurations that are not yet covered in literature can be conducted.
\end{abstract}

Keywords: trash-rack; CFD; turbulent models; head loss

\section{Introduction}

With growing ecological awareness, share of renewable energy in total energy production is rapidly increasing. Different designs in hydro and wind turbines are constantly being investigated to produce greater efficiency, where usage of numerical analysis provide great insight into fluid flow phenomena and guidelines for design changes [1], [2]. Analysis can be conducted for the whole turbine or for particular parts, where improvement in design of single part of turbine contributes to whole turbine efficiency. In this work analysis of single part of hydroelectric power plant will be considered. Trash-racks are installed at the intake of hydroelectric power plants to prevent large debris from entering turbine which could damage turbine parts and cause problems in power plant operation. 
Installation of trash-rack causes disturbance in fluid flow which causes inevitable energy losses. To minimize these losses trash-rack and bar design parameters are carefully chosen. Influence on fish migration and fish mortality is increasingly taken into consideration when discussing trash-rack design [3]. Increased awareness caused demand for change in design of trash-racks, where larger blockage of fluid flow and smaller approaching velocities provide better design regarding fish species, but causes greater losses and reduce turbine efficiency.

To determine energy losses, number of experimental investigations on trash-racks were conducted. Fluid flow around angled rectangular bar racks and influence of different cross sections (rectangular, bar with rounded leading edge and streamlined bar) were analysed in Tsikata et al. [4], [5]. Raynal [6], [7] investigated influence of angled trash-racks and Albayrak [8] investigated influence of angled trash-racks and angled bars.

In experimental set-up rack configurations need to be scaled down due to physical limitations of experimental flumes. In Albayrak et al. [8] scale effects were investigated for 1:1 and 1:2 model scales where for some configuration difference in head loss was $15 \%$. Head loss equations proposed in experimental studies usually give good agreement only for specific range of parameters. Investigation of these parameters is restricted with physical limitations and requires extensive research to find correlation between parameters that could be implemented in head loss equation. Numerical studies provide solution for these problems.

There are only a few experimental studies that investigate flow around trash racks. In Raynal et al. [9] numerical simulation was conducted in OpenFOAM which was validated with their previous experimental work. In work by Paul et al. [10] numerical 3D analysis of fluid flow past 3 and 7 submerged bar-racks was conducted in Ansys CFX where it was shown that numerical analysis overpredicts head loss coefficient compared to the experimental results. In Åkerstedt et al. [11] submerged rectangular and biconvex shaped bars were investigated for different angles of attack. In his work simplification was used with periodic boundary conditions and two-dimensional fluid flow domain.

In this work 3D numerical analysis of trash-rack is compared with experimental results taken from Tsikata [5] to analyse simulation parameters. Influence of boundary conditions and numerical mesh on simulation results is considered. Simulations with different turbulent models were conducted to select a model that produces the best agreement with experimental results. Parameters that produce the best agreement will be used in future numerical investigations that would consider different cross sections and allow numerical analysis of real turbine intake geometries.

\section{Problem formulation}

Geometry considered for turbulence model validation was small-scale set-up from [5] which is shown in figure 1. Geometry width B was set to $0.184 \mathrm{~m}$ which is the width of the test section insert that was placed in $0.2 \mathrm{~m}$ wide channel used in the experiment. Geometry height was set to $0.18 \mathrm{~m}$, which was the upstream water level that was maintained constant in the experiment. Length of domain was defined as 1.2 meters to provide enough length to develop fluid flow but to maintain reasonable number of elements. Trash-rack consisted of 3 bars with thickness $\mathrm{s}=0.012 \mathrm{~m}, \mathrm{~L}=0.076 \mathrm{~m}$ and bar spacing $b=0.058 \mathrm{~m}$. Bar height was $0.18 \mathrm{~m}$, that is, bars are considered fully submerged.

Fluid flow in trash racks usually ranges from 0.1 up to $2 \mathrm{~m} / \mathrm{s}$, because of that fluid velocities considered for numerical simulations were $0.2,0.4,0.6,0.8$ and $1 \mathrm{~m} / \mathrm{s}$. Simplification of problem was made, where domain height estimates free surface level which is constant for whole domain. This allows usage of single phase fluid flow model which reduces computational time, contrary to multiphase fluid flow model which is expected to better represent open channel flow that was conducted in the experiment, but requires significantly greater computational time.

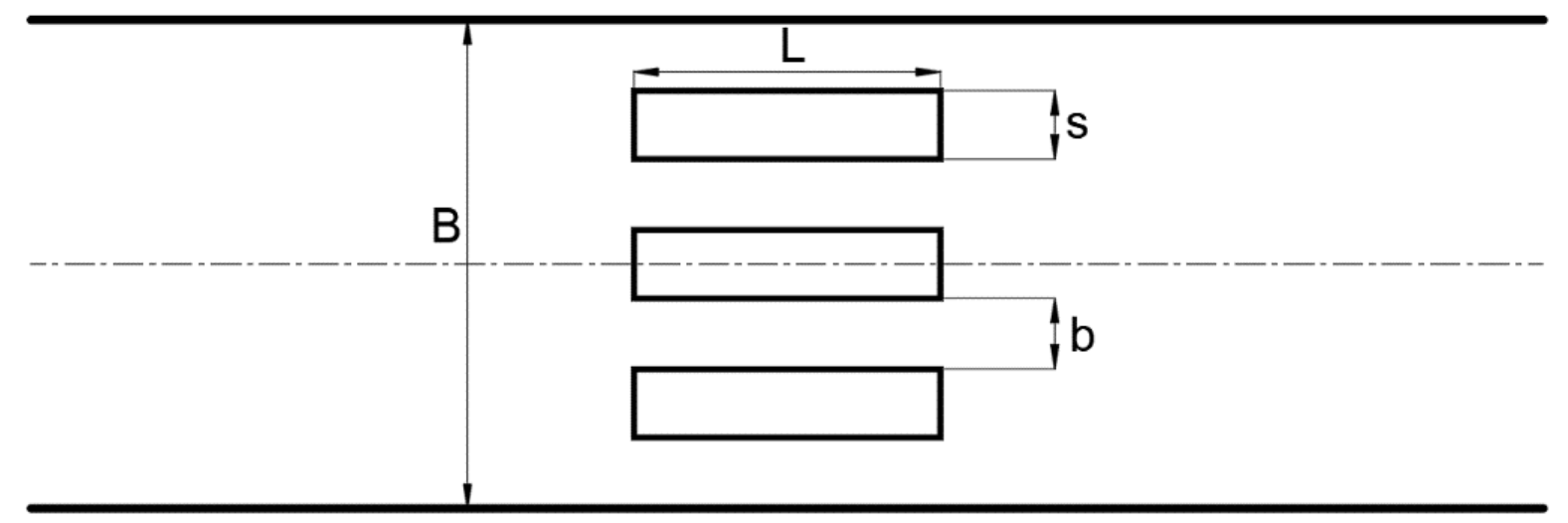

Fig. 1. Trash-rack configuration

Unstructured numerical mesh with $0.64,1.5$ and 3 milion elements was generated with evenly distributed layers of elements along domain height. Boundary layers are defined at bars and channel walls where first layer thickness was chosen to produce recommended $y+$ values for turbulence models that use wall functions (fig. 2.). 


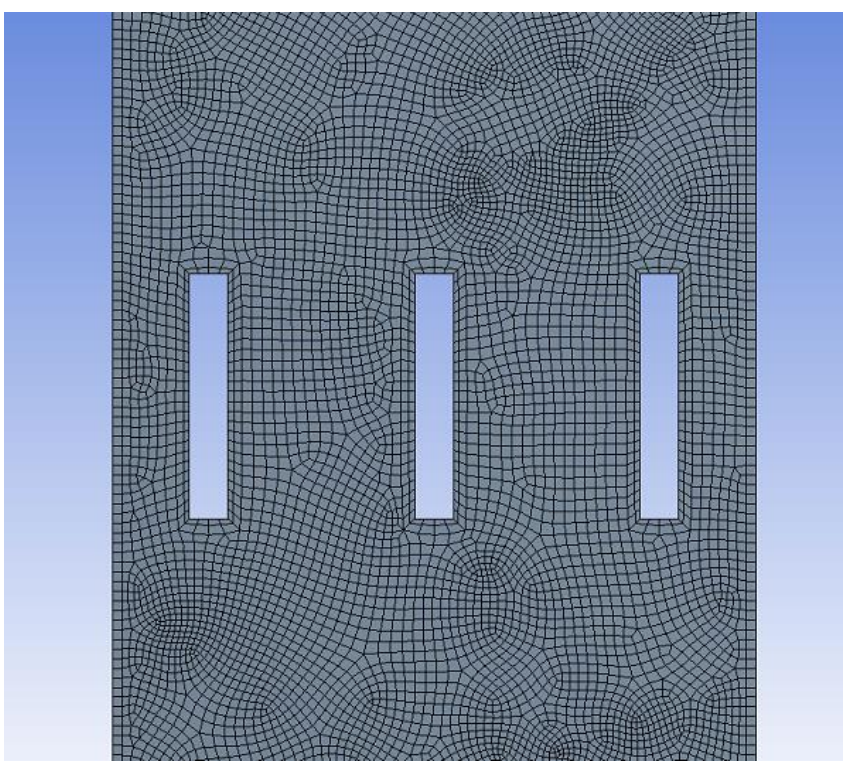

a)

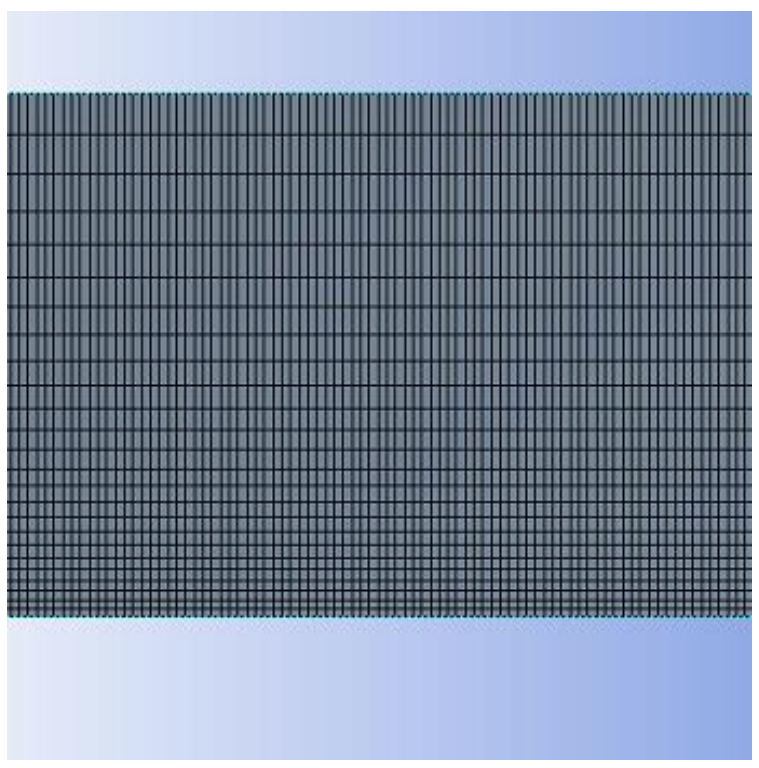

b)

Fig. 2. Mesh around bars for 640000 elements for a) top view and b) side view

Trash-rack configuration head loss was represented with dimensionless coefficient that was determined from equation:

$$
h^{*}=\Delta h \frac{2 g}{U^{2}}
$$

Where $U$ is fluid flow velocity at upstream profile, $\Delta h$ was defined as pressure difference of total pressures at upstream and downstream profiles divided with gravity constant and water density:

$$
\Delta h=\frac{p_{t o t, u}-p_{t o t, d}}{\rho g}
$$

Results were obtained for upstream and downstream profiles and impact of profile position selection will be considered.

\section{Simulation}

Simulation was conducted in ANSYS Fluent. Influence of boundary conditions was considered. In all simulations inlet was defined as velocity inlet, outlet as pressure outlet, top wall as symmetry and wall bars were considered as wall boundary condition. For simulation A bottom and side walls were considered no slip which corresponds to investigated experimental setup. For simulation B bottom wall remained no slip where side walls were defined as symmetry. This represents simulation when fluid flow around greater number of bars is examined.

To reduce numerical mesh, therewith computational time, only periodic part of domain is considered. It must be noted that for described simplification domain consisting of only one bar is usually used. Also, in considered experiment distance from outermost bars to channel walls is not equal as distance between inner bars which should be taken into consideration. To examine only influence of boundary condition, the same geometry and numerical mesh is used for all simulations. For the simulation $\mathrm{C}$ bottom wall was considered symmetry and side walls had no slip condition.

This also comes as simplification where domain represents periodic part of domain, considering that fluid flow along height of the channel is uniform when bar cross section is unchanged. Boundary condition for different simulation can be observed in table 1 .

\begin{tabular}{|l|c|c|c|c|c|c|}
\hline & top wall & inlet & outlet & wall bars & side walls & bottom \\
\hline Simulation A & symmetry & velocity inlet & pressure outlet & no slip & no slip & no slip \\
\hline Simulation B & symmetry & velocity inlet & pressure outlet & no slip & symmetry & no slip \\
\hline Simulation C & symmetry & velocity inlet & pressure outlet & no slip & no slip & symmetry \\
\hline
\end{tabular}

Table 1. Boundary conditions for simulations

Head loss coefficient measurements were conducted for two pairs of cross sections to investigate influence of measuring points locations. First pair of profiles consisted of domain inlet (located at $0.4 \mathrm{~m}$ upstream from bar leading edge) and outlet profile (located at $0.8 \mathrm{~m}$ downstream from bar leading edge). 
In Ghamry [12] and Paul [10] profiles located at 14.5L upstream and 14.5L downstream were chosen because it was argued that their locations will not have a significant impact on the solutions obtained. Because of that, second pair of profiles was chosen with profiles located at $0.3 \mathrm{~m}$ upstream from bar leading edge and $0.4 \mathrm{~m}$ downstream from bar leading edge (fig. 3.). The origin of the coordinate system is defined at the bar leading edge. It was noticed that location of measuring points has a great influence on data comparison and impact of profile position selection will be discussed in results section.

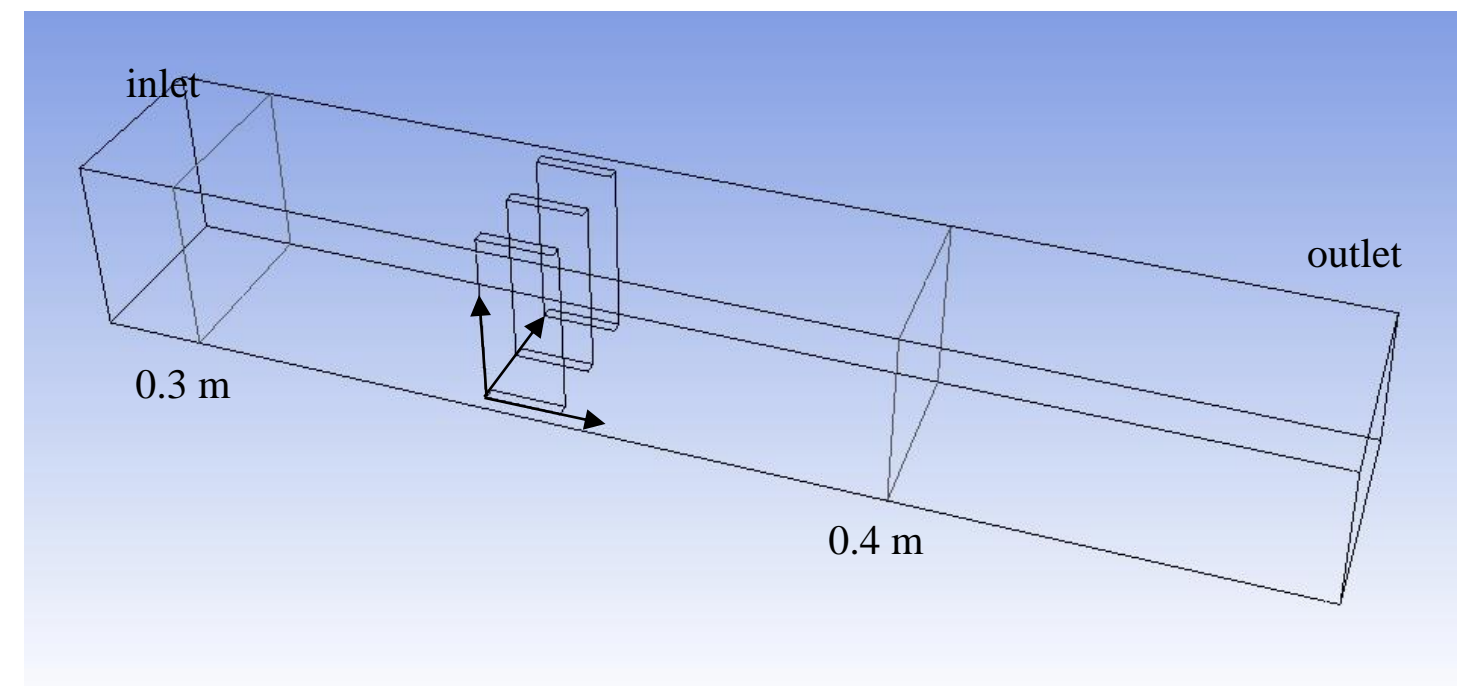

Fig. 3. Locations of upstream and downstream profiles used for measurements

Fluid flow was considered steady and turbulent for all simulations. Three dimensional Reynolds-averaged NavierStokes (RANS) equations were solved, where following two equation turbulence closure models were considered: k- $\varepsilon$ standard, k- $\varepsilon$ realizable, k- $\omega$ standard and k- $\omega$ SST. Simulations were conducted for scalable and standard wall functions.

\section{Results}

Location of head loss measurement caused great variation in results, where difference in loss coefficient was mostly in the range of $10-20 \%$. In many literature the exact location of measuring points in streamwise direction for head loss coefficient calculation is not explicitly defined, which can cause variation in experimental and numerical results. Results gained at inlet and outlet profiles produced greater values of coefficient $\mathrm{k}$, and with that greater difference from experimental results. Thus, those results are omitted from future discussion and only results gathered at profiles $0.3 \mathrm{~m}$ upstream and $0.4 \mathrm{~m}$ downstream will be considered.

Difference in considered wall functions can be noticed at low velocities $(0.2 \mathrm{~m} / \mathrm{s})$, but with velocity increasement scalable and standard wall functions produce the same results, thus only results for standard wall functions are presented at graphs. Simulation results for 0.64, 1.5 and 3 million elements are presented in figures 4, 5 and 6.

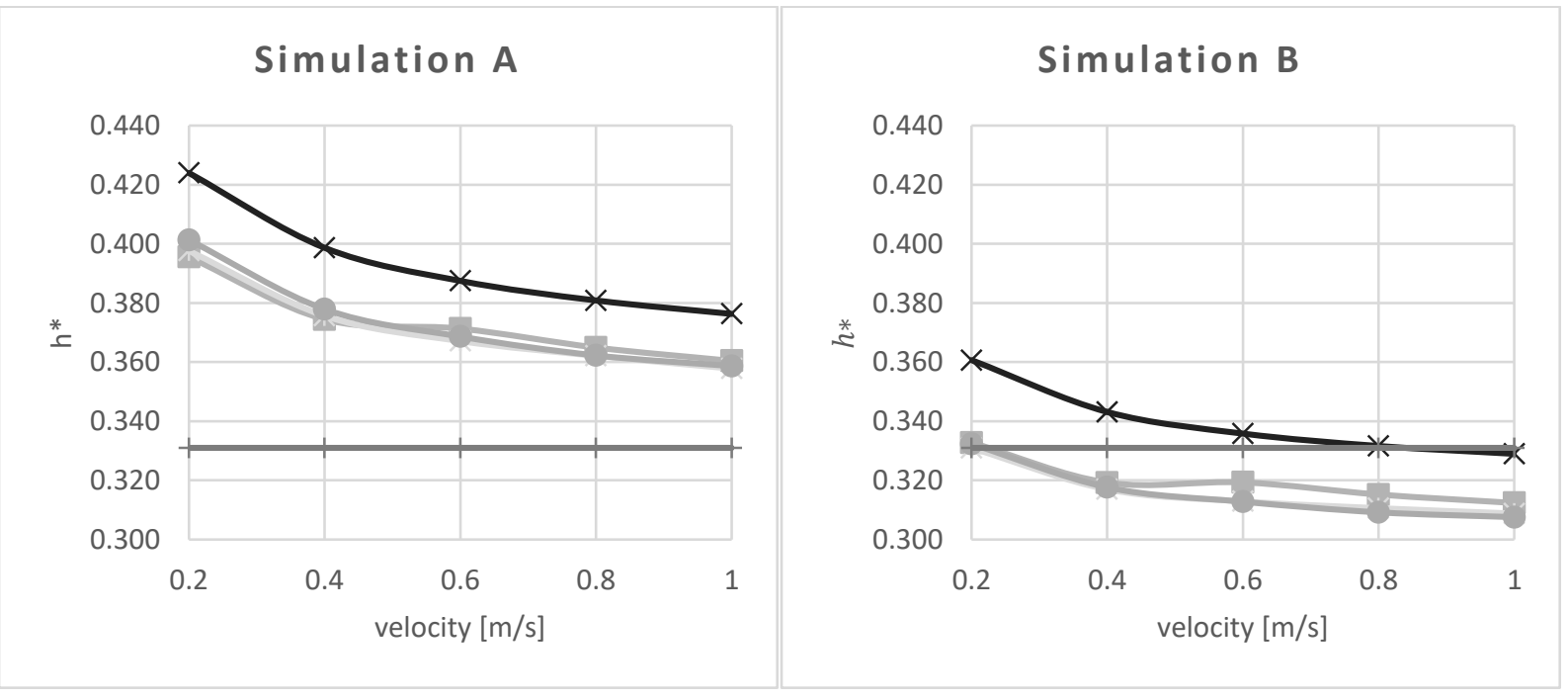




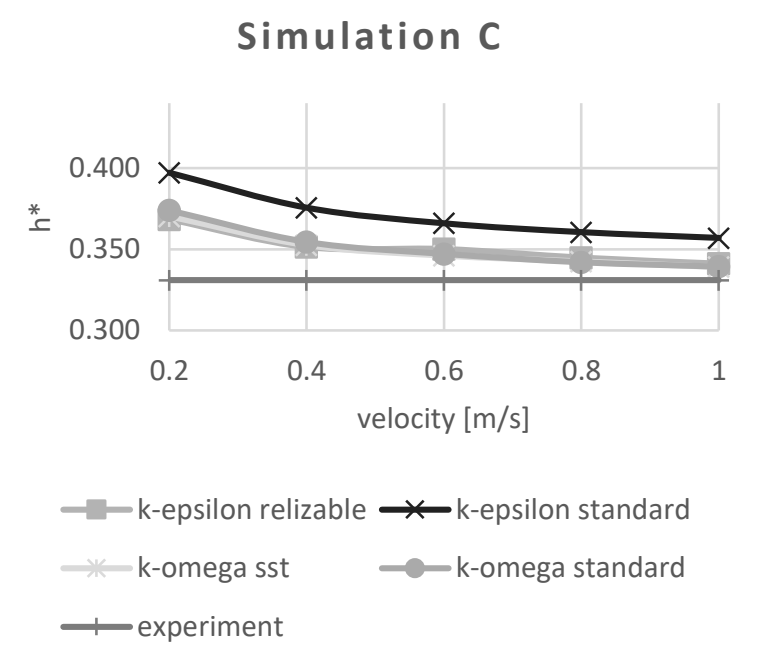

Fig. 4. Loss coefficient $\mathrm{h}^{*}$ for different turbulence models for numerical mesh consisting of 640000 elements

It can be seen that with greater number of elements mesh independent solution is obtained for simulations with 1.5 million (figure 5) and 3 million elements (figure 6). In the figures it can be seen that k-omega sst, k-omega standard and $\mathrm{k}$-epsilon realizable for all considered simulations produce mostly similar results.

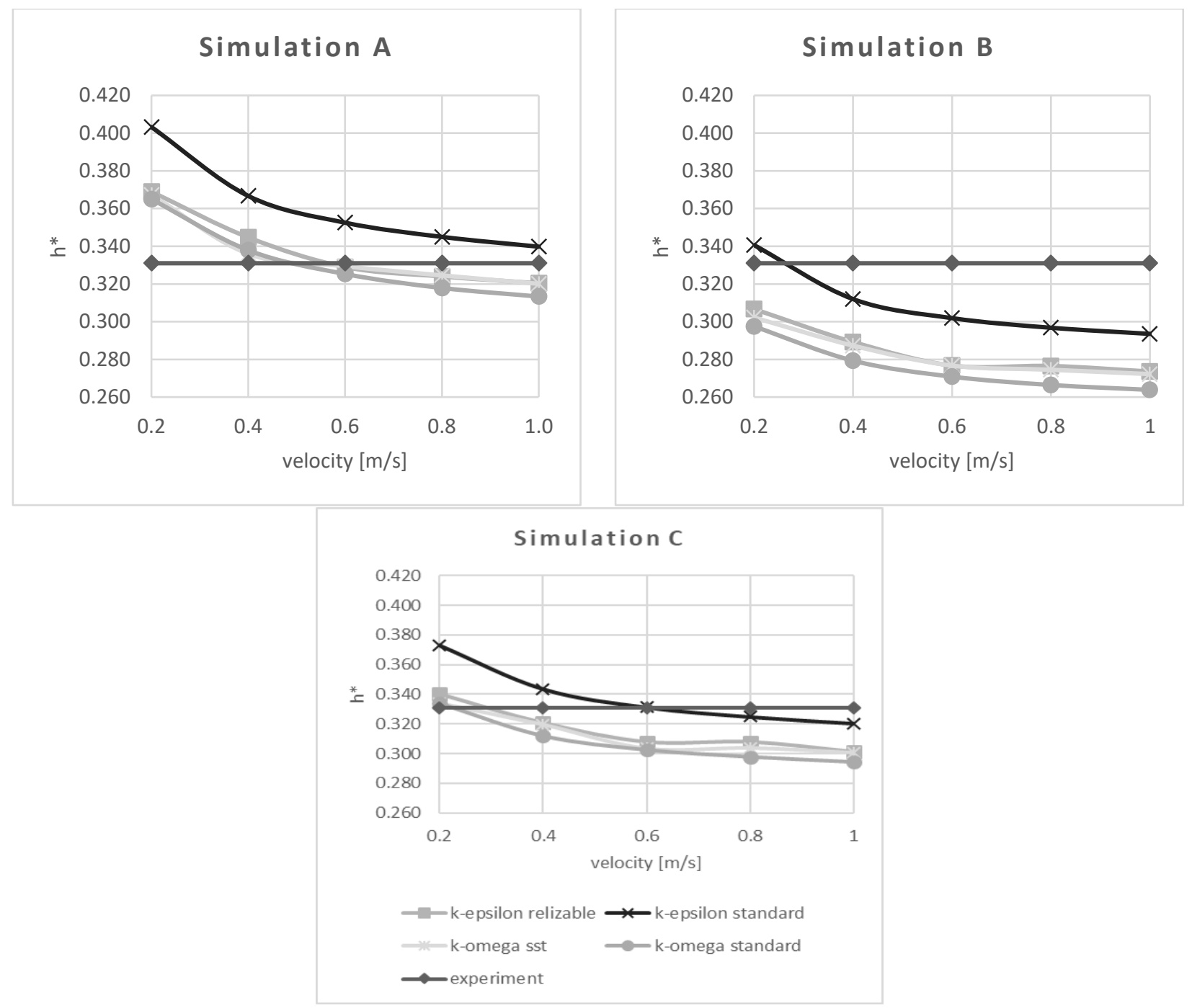

Fig. 5. Loss coefficient $\mathrm{h}^{*}$ for different turbulence models for numerical mesh consisting of 1.5 million elements 
K-epsilon standard produces from 5 to $10 \%$ increased head loss coefficient then other turbulent models, depending on the simulation. It must be noted that k-epsilon standard produced stable solution for all simulations, where other used turbulent models had present oscillation in head loss coefficient calculation during simulation. Because of that results presented in graphs are calculated as an average value of head loss coefficient during those oscillations.

From the results it can be seen that Simulation B, where side walls are described as symmetry boundary condition has much lower loss coefficient. This indicates that there is great influence of the channel side wall on fluid flow around trash-rack that have lesser number of bars. Simulation C, where bottom wall is described as symmetry boundary condition also generates decreased head loss coefficient which also indicates important influence of bottom wall when considering fluid flow with small water heights. For simulation A, which uses wall functions for both side walls and bottom wall, the best agreement with experiment can be seen. This can be expected because boundary conditions used for this simulations represent real experiment conditions. This points to the fact that simplifications in numerical simulations must be carefully chosen.

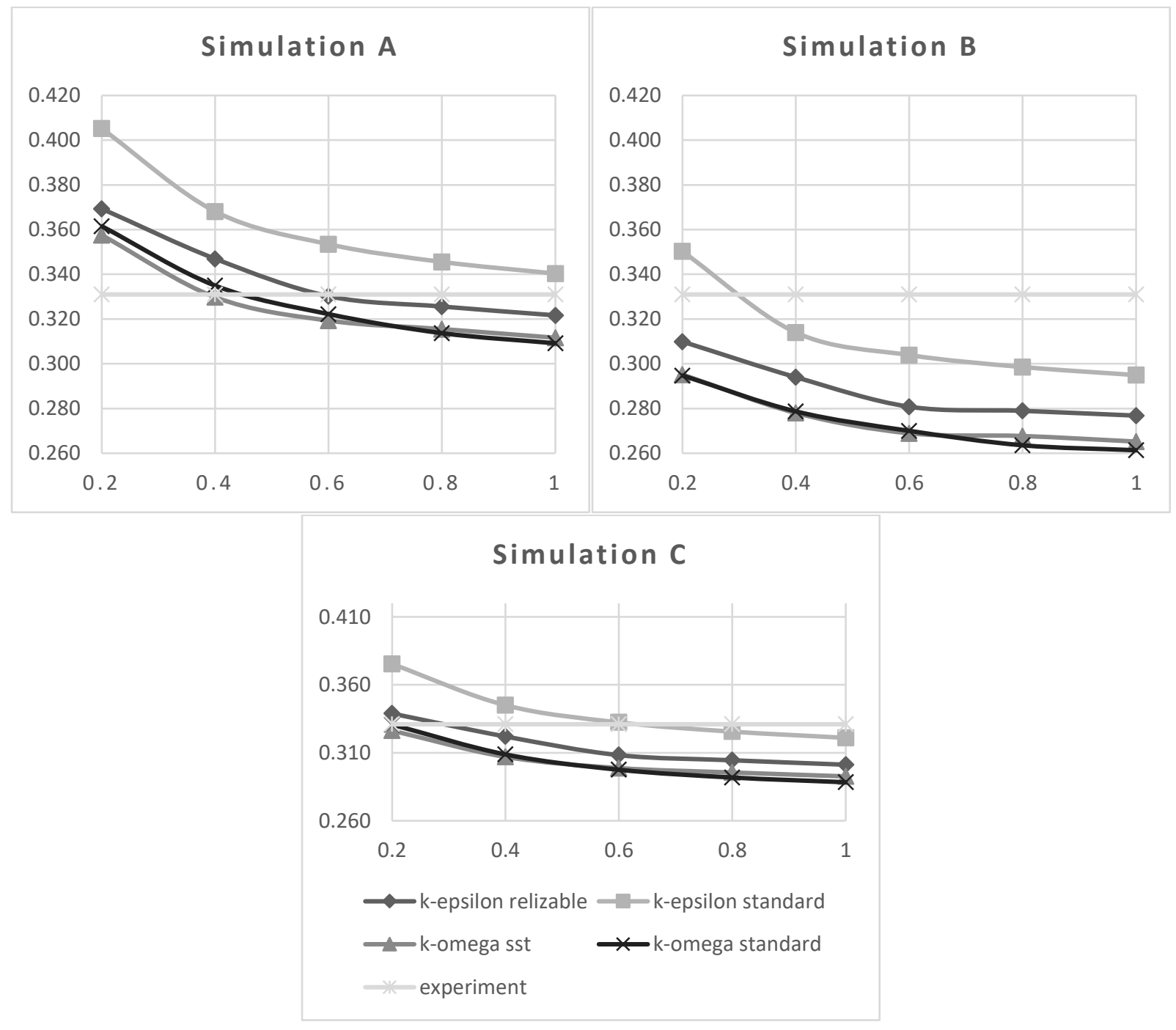

Fig. 6. Loss coefficient $h^{*}$ for different turbulence models for numerical mesh consisting of 3 million elements

\section{Conclusion}

In this work influence of choice of turbulent model, wall functions, boundary conditions and measuring location on results agreement of simulation with existing experimental results was investigated. Simplification was made, where domain height represented water surface level which is known from the experiment. This simplification allowed usage of single phase fluid flow simulation which uses much less computational resources than two phase fluid flow that is usually used for these types of experiments. Results obtained using this simplification provided good agreement with the experiment. 
Influence of numerical mesh was also considered, where mesh independence was accomplished for 1.5 million elements. It was shown that position of measurement profiles has influence on obtained results, where for best agreement these locations should be explicitly defined in experiment measurements.

Numerical simulations were conducted for different turbulence models, k-epsilon realizable, k-epsilon standard, komega sst and k-omega standard. It was observed that k-epsilon standard provides stable results, where other turbulent models shown head loss coefficient oscillations during simulation iterations and results that are presented in this work show average value of these oscillations. It can be seen that k-epsilon standard gives greater head loss coefficient than other considered models which mostly generate similar results.

It can be also noticed that with increased velocity disagreement with experimental data is reduced. Reason for this could be in mesh requirement for lower velocities. If standard wall functions are used (where requirement for $y+$ is over 30), with velocity decrease first boundary layer thickness must be increased. For considered geometry where distance between walls is small, this can cause unsatisfactory discretization of domain space. For lower velocities enhanced wall treatment should be considered which could provide better solution.

Investigation of boundary conditions showed great difference in results. For small scale experiments, influence of side and bottom walls must be taken into consideration and periodicity simplifications should be avoided. Future investigation should be conducted with real scale experiments, where for greater number of bars influence of side walls could be neglected and simulation simplification using only one bar could be made. The question still remains regarding bottom wall, where experiments are usually made in shallow channels where bottom wall influence is important, contrary to the turbine intake that has greater depth. This suggests that full turbine intake geometry should be used to obtain most precise head loss coefficients for chosen geometry, which is possible with numerical simulations and increasing computational power.

Presented conclusions should be further evaluated with other available experiments, where if confirmed, they can be used in future numerical investigation of inclined trash-racks, where trash-rack configuration and bar cross section can be optimized for given turbine intake.

\section{References}

[1] Mălăel, I., Gherman, B.G. \& Porumbel, I. (2016). Increase the smart cities development by using an innovative design for vertical axis wind turbine. Proceedings of the 27th DAAAM International Symposium, pp. 0506-0513, ISBN 978-3-902734-08-2, ISSN 1726-9679, DOI: 10.2507/27th.daaam.proceedings.076, Published by DAAAM International, Vienna, Austria

[2] Malalel, I., Dragan. V \& Gherman, G. B. (2016). Turbulence Intensity Effects on the Vertical Axis Wind Turbine Starting Efficiency. Proceedings of the 26th DAAAM International Symposium, pp. 0974-0979, Published by DAAAM International, ISBN 978-3-902734-07-5, ISSN 1726-9679, DOI: 10.2507/26th.daaam.proceedings.137

[3] Szabo-Meszaros, M. et al. (2018). Experimental hydraulics on fish-friendly trash-racks: an ecological approach. Ecological Engineering. Vol 113, pp. 11-20.

[4] Tsikata, J. M., Tachie, M. F. \& Katopodis, C. (2009). Particle image velocimetry study of flow near trashrack models. Journal of Hydraulic Engineering, Vol. 135, No. 8., pp. 671-684.

[5] Tsikata, J. M., Tachie, M. F. \& Katopodic, C. (2014). Open-channel turbulent flow through bar racks. Journal of Hydraulic Research, Vol. 52, No. 5., pp. 630-643.

[6] Raynal, S., Courret, D., Chatellier, L., Larinier, M. \& David, L. (2013). An experimental study on fish-friendly trashracks- Part 1. Inclined trashracks. Journal of Hydraulic Research, Vol. 51, No. 1, pp. 56-66.

[7] Raynal, S., Chatellier, L., Courret, D., Larinier, M. \& David, L. (2013). An experimental study on fish-friendly trashracks-Part 2. Angled trashracks. Journal of Hydraulic Research, Vol. 51, No. 1, pp. 67-75.

[8] Albayrak, I., Kriewitz, C. R., Hager, W. H. \& Boes, R. M. (2018). An experimental investigation on louvres and angled bar racks. Journal of Hydraulic Research, Vol. 56, No. 1, pp. 59-75.

[9] Raynal, S., Chatellier, L., David, L., Courret, D. \& Larinier, M. (2013). Numerical simulations of fish-friendly angled trashracks at model and real scale. Proceedings of 25th IAHR World Congress, Chengdu, China.

[10] Paul, S. S. \& Adaramola, M. S. (2014). Analysis of Turbulent Flow Past Bar-Racks. Proceedings of ASME 2014 International Mechanical Engineering Congress and Exposition. American Society of Mechanical Engineers.

[11] Åkerstedt, H. O., Eller, S. \& Lundström, T.S. (2017). Numerical Investigation of Turbulent Flow through Rectangular and Biconvex Shaped Trash Racks. Egineering, Vol. 9, No. 05, pp. 412.

[12] Ghamry, H. K. \& Katopodis C. (2012). Numerical investigation of turbulent flow through bar racks in closed conduits. Proceedings of the 9th International Symposium on Ecohydraulics, Vienna, pp. 17-21. 